\title{
Editorial: Ecology and Evolution of Plants Under Domestication in the Neotropics
}

\author{
Alejandro Casas ${ }^{* *}$, Ana H. Ladio ${ }^{2}$ and Charles R. Clement ${ }^{3}$ \\ ${ }^{1}$ Instituto de Investigaciones en Ecosistemas y Sustentabilidad, Universidad Nacional Autónoma de México, Morelia, Mexico, \\ ${ }^{2}$ Instituto de Investigaciones en Biodiversidad y Medio Ambiente, Universidad Nacional del Comahue, Bariloche, Argentina, \\ ${ }^{3}$ Departamento Tecnologia e Inovação, Instituto Nacional de Pesquisas da Amazônia, Manaus, Brazil
}

Keywords: genetic resources, human guided evolutionary processes, human selection, landscape domestication, origins of agriculture, Tropical Americas

Editorial on the Research Topic

Ecology and Evolution of Plants Under Domestication in the Neotropics

\section{INTRODUCTION}

The earliest studies on domestication and the origins of agriculture identified the Americas, particularly the Neotropics, as one of the settings with the earliest experiences of these processes in the world (Darwin, 1859, 1868; de Candolle, 1882; Vavilov, 1926). For a long time, Mesoamerica, and the Andean region were considered the main areas of origin of agriculture, but more recently Amazonia was shown to be similarly important (Clement et al., 2015; Levis et al., 2017). Analyzing how similar the processes were among these main regions and how much they influenced each other remain mostly unexplored. This is relevant to understand how the domestication processes originated and diffused throughout the whole continent, as well as how ancient and current human cultures of the region practiced-and practice-plant domestication (Casas et al., 2017). In addition, it is relevant to comprehend how peoples have practiced landscape domestication, which involves human manipulation of landscapes resulting in ecological changes at that scale, as well as more productive landscapes, congenial for humans (Clement, 1999).

This research topic of Ecology and Evolution of Plants under Domestication in the Neotropics showcases 20 articles analyzing in depth 17 species in several Neotropical regions, as well as dozens of species from various perspectives. The studies include evolutionary, phylogeographic, ethnobotanical, population genetics, pollination biology, and ecological approaches. All are valuable contributions that reflect the state-of-the-art and trends in research on domestication in the Neotropics, and put new questions and hypotheses into perspective for further studies.

\section{Domestication as an Evolutionary Process}

Several articles of the Research Topic review and analyse current issues on domestication as an evolutionary process and the contribution of such perspective to constructing general evolutionary theory. Particularly, some authors analyse parallel and convergent evolution associated to domestication, the shaping of phenotypes by human and non-human forces, as well as domestication as on-going process that allows studying how evolution operates and can be analyzed. These aspects are reviewed by Pickersgil and Chen et al., and illustrated with case studies in Capsicum annuum and Phaseolus lunatus by Luna-Ruiz et al. and Cuny et al., respectively. All these studies exemplify the different nature of human and natural forces influencing evolution, and exhibit domestication as study model for analyzing evolutionary processes. 
Pickersgill analyzed the nature of changes in phenotypic traits involved in domestication, which are commonly produced by complex genetic networks and quantitative trait loci. Domestication has been historically analyzed as a diversification process, resulting in variants adapted to different uses, environments, and agronomic conditions. Similar diversification traits may be shared by closely related species controlled by homologous genes (parallel evolution) or by distantly related species controlled by non-homologous genes (convergent evolution). Understanding the nature of traits resulting from domestication and diversification is not always easy and may have different meanings according to the scale at which these processes are visualized. Crops domesticated in the Neotropics have responded to human of selection for diverse purposes, changing in many different traits and providing examples of both parallel and convergent evolution, but data are still insufficient to arrive at conclusions about the relative roles of these two processes in domestication and diversification.

Considering domestication as a model for analyzing the genetics of evolution, Chen et al. studied how biotic, abiotic, and human selective forces shaped the phenotypes of domestic plants. From a quantitative genetics approach the authors emphasized the effects of abiotic and biotic interactions of microbial and insect assemblages on phenotypes, availability of nutrients, humidity, among other factors, and called attention to the need to understand local adaptation. This approach has theoretical relevance for evolutionary studies, as well as applicable consequences for evolutionary criteria for sustainable management of agricultural practices.

Luna-Ruiz et al. analyzed shifts in plant chemical defenses of C. annuum associated with domestication in Mexico. They assumed that comparing wild and domesticated forms can elucidate how crop domestication influences biotic and abiotic interactions, including the chemical defenses involving capsaicinoids. Capsaicin is a secondary metabolite in the chile fruit that mediates interactions with seed dispersers (birds), and with seed predators (fungi, insects, and rodents). The authors explored the evolutionary ecology of Capsicum and humanCapsicum interactions to test how domestication shifts plant chemical defenses. Their review examined the ways in which incipient domestication through "balancing selection" in wild C. annuum populations may have led to the release of selective biotic and abiotic pressures. Then they characterized cultivated material with chemotypes, morphotypes, and ecotypes found in low frequencies in the wild, probably related to different cultural uses, cropping systems, and ecogeographic regions.

Cuny et al. studied seed size of P. lunatus in relation to competition of beetle larvae. The authors explored the hypothesis that larger seeds of beans decrease competition among beetle larvae, which indicates that gigantism of seeds not only favored human desired characters but also plants fitness. The authors found a negative correlation between the initial egg number on a seed and the weight of female beetles that emerged from the much smaller wild seeds. Similarly, beetle survival was found to be negatively correlated with competition intensity only on wild seeds. The larger seed size of cultivated beans mitigates the potential negative effects of larval intraspecific competition to plants, which controls the size of populations. The results suggest that human selection for larger seeds has reduced the intensity of intraspecific larval competition of the beetle Zabrotes subfasciatus.

Pedrosa et al. evaluated the on-going domestication of Pourouma cecropiifolia populations cultivated in Western Amazonia. The authors compared fruit characteristics between wild and domesticated populations to quantify the direct effects of domestication. Also, they examined differences in vegetative characteristics and changes in seed:fruit allometric relations to explore characteristics that are not under direct human selection. Although they could not clearly discriminate the effects caused by human selection and consequences associated with environmental changes, they suggest that the allometric differences between fruits and seeds of wild and domesticated plants can be used in future studies as an additional parameter of the domestication syndrome.

\section{Origins and Diffusion of Domestication}

Several contributions used phylogeographic and phylogenomic approaches to analyse the origin and dispersal of crops. These contributions illustrate cases of important crops from the Neotropics and provide methods and theory for further studies on this important issue. Chacón-Sánchez and Martínez-Castillo studied ( $P$. lunatus), whose wild populations are widely distributed from Mexico to northern Argentina. By using genome-wide SNP markers, they explored the number of domestication events, and whether two Mesoamerican gene pools can be identified. They confirmed the two Mesoamerican gene pools and suggested that the differentiation of wild Mesoamerican pools was previous to domestication, and concluded that there was one main Western Mesoamerican domestication event, as well as confirming the Andean gene pool from Ecuador and Peru.

With a similar approach, Guerra-García et al. analyzed the genomics of the P. coccineus, naturally distributed from northern Mexico to Panama, exploring the history of domestication events and loci associated with natural and human selection. By genotyping SNPs, the authors identified a monophyletic clade of cultivated populations suggesting a single domestication event in the Trans-Mexican Volcanic Belt, instead of the two events suggested by previous studies with SSR markers. The study identified 24 SNPs associated with domestication, mainly of flower and pod characters, another 13 loci related to crop diversification and others associated with natural selection.

Moreira et al. analyzed the case of Crescentia cujete and $C$. amazonica. Previous studies by Aguirre et al. (2012) identified strong differences in gene lineages of wild and cultivated populations of this species in Mexico, even in the Mayan homegardens of the Yucatán Peninsula where both types coexist, which lead them to suggest the origin of domestication of C. cujete in Central or South America. The authors explored the relationship between Mesoamerican and Amazonian $C$. cujete, their morphological and genetic variation, and possible routes of dispersal. They concluded that domesticated C. cujete were introduced into the Amazon Basin and Mexico, sharing a common ancestry with a currently unknown origin. The 
occurrence of wild populations in Mexico and the higher diversity of cultivated C. cujete from Mesoamerica, compared to Amazonia, suggest that its origin may be in Central America, but a more extensive sampling is still needed to test this hypothesis.

Clement et al. examined the origin and dispersal of domesticated Bactris gasipaes. They identified the wild relative of the domesticated landraces, and examined three hypotheses about the origin of domestication (either southwestern Amazonia, northern South America, or multiple independent events). The authors modeled the potential distribution of wild and domesticated palms, identified the origin with cpDNA sequences, and post-domestication dispersal routes with nuclear microsatellites. The phylogeographic studies confirmed southwestern Amazonia as the origin of domestication, while nuclear markers confirmed two dispersals, one along the Ucayali River with starchy fruits for fermentation, into western Amazonia, north-western South America, and Central America; the other along the Madeira River into central and then eastern Amazonia.

Chávez-Pesqueira and Núñez-Farfan reviewed the genetics of the domestication of Carica papaya, which has been proposed as a Mesoamerican domesticate for a long time, a hypothesis supported in this study because wild populations are distributed in southern Mexico and Central America. In addition, phylogenetic studies indicate that the closest relatives of Carica are the genera Horovitzia and Jarilla, both endemic to Mesoamerica. The authors emphasize the study of wild populations from Mesoamerica and conclude with the importance of more extensive sampling and genomic approaches for precisely identify the events of domestication and routes of dispersal.

\section{Landscape Domestication}

A group of articles focuses on processes of incipient domestication and the association of this type of plant management with landscapes that are transformed for human needs, which has long been considered a process of domestication, since landscapes are socio-ecological constructions (Casas et al., 1997). This is a relatively recent approach (Clement, 1999) and several articles of this Research Topic contribute with case studies that allow constructing theories and methodological approaches. Morales et al. used an ethnobotanical perspective to analyse the use of plant species as fuelwood in Patagonian rural communities; they explored the fuelwood gathering patterns in relation to different landscapes according to their degree of domestication. They found that less domesticated landscapes were less intensely used as sources of fuelwood, provided fewer species that were also less intensely used and had lower use versatility than in domesticated landscapes, which, although less rich in species composition, with mostly exotic species, were more intensely used. They found that the landscape units have spatial continuity, including semidomesticated landscapes, in response to ecological gradients and types of management. Landscapes with medium and high domestication levels provide exotic (and native) plant species, decreasing pressure on native species.
Furlan et al. examined landscape domestication by studying homegardens of the peri-urban areas of the city of Iguazú, Argentina. Using ethnobotanical and ecological approaches, they documented the different types of management of 66 perennial species and varieties, their distribution and abundance, and their influence in shaping local landscapes. In addition, the authors emphasized the importance of local knowledge for managing and maintaining native species in homegardens of the Atlantic Forest.

Cruz-García analyzed the motivations of people to manage food plants, which is a crucial topic to understand how management and domestication starts today and how it could have started in the past. She studied plant management practiced by people in a rural village in Peruvian Amazonia, documenting practices in forests and agroforestry systems. The interest of people to have access to valuable resources, their abundance, and the ease of managing them are major factors influencing people's decisions. The study is a theoretical contribution to understand the origins of plant management and its ecological and evolutionary consequences, as well as for food security programs.

Betancurt et al. documented incipient domestication processes in plants of urban parks of San Carlos de Bariloche, Argentina, in the Andino Norpatagonica Biosphere Reserve. Incipient processes of domestication are under studied and most are from rural contexts; therefore this contribution is doubly important, documenting what urban people do with plants, how they manage them, and when, where and how they start processes of domestication. The authors analyzed composition and different management practices of woody species in parks with different environmental and socioeconomic characteristics, hypothesizing that species richness of exotic plants would be higher than native, mainly ornamental species, and management type would vary according to the environment and socioeconomic aspects of the park. Most species were exotic; however, the authors reported native species, some with signs of incipient domestication, which form part of the local biocultural heritage, and that help to preserve natural ecosystems and promote appreciation of local biocultural values.

Levis et al. examined how people domesticated Amazonian forests, which have been managed by people for millennia. They documented plant management and its consequences on the structure of vegetation in 30 sites, where they recorded the following practices: (1) removal of non-useful plants, (2) protection of useful plants, (3) attraction of non-human animal dispersers, (4) transportation of useful plants, (5) selection of phenotypes, (6) fire management, (7) planting of useful plants, and (8) soil improvement. These practices allowed the authors to explain how patches of vegetation dominated by useful plants could have been formed in the past.

Following similar principles, Reis et al. analyzed management and domestication of araucaria forests in southern Brazil. These forests are currently managed to produce Ilex paraguariensis under Araucaria angustifolia. The authors focused their analysis on I. paraguariensis, A. angustifolia, and Bromelia antiacantha, and documented management practices, demographic structure and genetic diversity in farming zones and in a protected area. The three species are intentionally promoted with practices of protection, transplanting, and/or selection. 


\section{Genetic Resources Management and Policies}

Finally, the Research Topic includes some policy-related articles since the themes analyzed are connected with genetic resources diversification, use and conservation. Themes like genetic improving through plant breeding and genetic engineering, biosafety, and conservation policies from general scope to specific cases are issued. Although this is a controversial subject that deserves more extensive analyses, studies and views showed in the Research Topic are examples of the spectrum of issues and approaches needed. Hernández Terán et al. provided a meta analysis of plant breeding and genetic engineering of rice, maize, canola, sunflower, and pumpkin, whose targeted and non-targeted traits are compared with their wild relatives and organisms improved without genetic engineering. The authors concluded that genetic modification by humans can be traced phenotypically when compared with their wild relatives, and that the magnitude of the phenotypic differences between crops with or without genetic engineering suggest consequences of genetic modification beyond the target traits. Cases in which the transgene, due to genetic interactions, causes unexpected phenotypes were identified in canola, sunflower, rice, and maize, but they could not rule out phenotypic plasticity nor the origin and specific context of domestication in different phenotypic scenarios. The authors conclude that further studies on phenotypic changes in human modified crops must include as many traits as possible, including non-target traits.

Sánchez de la Vega et al. studied the genetic variation of Cucurbita argyrosperma and its wild relatives across Mexico to identify the main areas of genetic diversity and differentiation, as well as to evaluate gene flow among wild and domesticated populations. Such an approach contributes to identify possible areas of domestication and design policies for conservation.

Mastretta-Yanes et al. present the initiatives of the National Commission for Knowledge and Use of Biodiversity (CONABIO) of Mexico to study and sustainably use and conserve the genetic diversity of crops and their wild relatives. These national initiatives focus on the sources of variation available for domestication, the context in which domestication occurs, and an important challenge, environmental change. The initiative concentrates on: (1) pilot research projects on genetic diversity of Mexican cultivars and wild relatives, (2) an information system developed by CONABIO that allows data on agrobiodiversity and genetic diversity to be analyzed, archived, and made public, (3) enhancing collaboration among research groups, civil organizations, and education institutions to accelerate

\section{REFERENCES}

Aguirre, X., González, A., Eguiarte, L., and Casas, A. (2012). Large and round: morphological and genetic consequences of artificial selection on the gourd tree Crescentia cujete by the Maya from the Yucatán Peninsula, Mexico. Ann. Bot. 109, 1297-1306. doi: 10.1093/aob/mcs068

Casas, A., Caballero, J., Mapes, C., and Zárate, S. (1997). Manejo de la vegetación, domesticación de plantas y origen de la agricultura en Mesoamérica. Bot. Sci. 61,31-47. doi: 10.17129/botsci.1537 participatory research, and (4) implementation of public policy recommendations and participatory research congruent with the reality of smallholders' needs in Mexico.

Velázquez-López et al. conducted pollination biology studies to analyse the mating system of wild and domesticated Gossypium hirsutum. Cultivated cotton is generally considered self-pollinated, but the mating system varies throughout the distribution of the metapopulations studied, and it should therefore be considered to have a mixed mating system rather than being primarily autogamous. This has consequences for strategies of conservation and biosecurity.

\section{CONCLUSIONS}

The contributions suggest the importance of studying the processes of parallel and convergent evolution in domestication, as well as the role of human and natural selection in this process. New gene sequencing techniques provide abundant information about origins of domestication and subsequent dispersal, and preliminary data show the Neotropics to be a diffuse mosaic of areas of origin of its main crops, rather than the centers of origin originally proposed by Vavilov and others. These proposals are being analyzed with new archaeological and genomic approaches and most probably will change our current view about origins of domestication, dispersal of crops, and production systems. Landscape domestication is a theoretically valuable concept, as the Amazonian, Mesoamerican, Andean, and Patagonian cases illustrate. Domestication has generated important genetic resources for meeting global and local needs that are crucial in the context of global change. Policies for enhancing understanding and conservation of genetic resources and processes shaping them are primary issues that require research and interaction of the academic sector with decision makers from household to global scales.

\section{AUTHOR CONTRIBUTIONS}

All authors listed have made a substantial, direct and intellectual contribution to the work, and approved it for publication.

\section{ACKNOWLEDGMENTS}

We wish to thank all the contributing authors for their efforts to make this issue a success. We also wish to thank the Frontiers in Ecology \& Evolution editorial and support teams for their patience and advice. 
population decline. Econ. Bot. 53, 188-202. doi: 10.1007/bf02 866498

Clement, C. R., Denevan, W. M., Heckenberger, M. J., Junqueira, A. B., Neves, E. G., Teixeira, W. G., et al. (2015). The domestication of Amazonia before European conquest. Proc. R. Soc. 282:20150813. doi: 10.1098/rspb.2015.0813

Darwin, C. (1859). On the Origins of Species by Means of Natural Selection, or the Preservation of Favoured Races in the Struggle for Life. London: John Murray.

Darwin, C. (1868). The Variation of Animals and Plants Under Domestication. London: John Murray.

de Candolle, A. (1882). Origine des Plantes Cultive'es. Paris: Germer Bailliere.

Levis, C., Costa, F. R. C., Bongers, F., Peña-Claros, M., Clement, C. R., Junqueira, A. B., et al. (2017). Persistent effects of pre-Columbian plant domestication on Amazonian forest composition. Science 355, 925-931. doi: 10.1126/science.aal0157
Vavilov, N. I. (1926). Origin and Geography of Cultivated Plants. Cambridge: Cambridge University Press.

Conflict of Interest Statement: The authors declare that the research was conducted in the absence of any commercial or financial relationships that could be construed as a potential conflict of interest.

Copyright (C) 2019 Casas, Ladio and Clement. This is an open-access article distributed under the terms of the Creative Commons Attribution License (CC BY).

The use, distribution or reproduction in other forums is permitted, provided the original author(s) and the copyright owner(s) are credited and that the original publication in this journal is cited, in accordance with accepted academic practice. No use, distribution or reproduction is permitted which does not comply with these terms. 